\title{
Comparison of thyroid hormone status between pre-eclampsia and normotensive pregnancy after 37 weeks
}

\author{
Mahalakshmi Aravazhi, Rashmi Ajit*, V. Breetha, S. Sruthi
}

Department of Obstetrics and Gynecology, Kanyakumari Government Medical College and Hospital, Tamil Nadu, India

Received: 20 January 2022

Accepted: 05 February 2022

*Correspondence:

Dr. Rashmi Ajit,

E-mail: rashmiajit15@gmail.com

Copyright: ( ) the author(s), publisher and licensee Medip Academy. This is an open-access article distributed under the terms of the Creative Commons Attribution Non-Commercial License, which permits unrestricted non-commercial use, distribution, and reproduction in any medium, provided the original work is properly cited.

\begin{abstract}
Background: Preeclampsia is the leading cause of maternal mortality in developing countries and is associated with a fivefold increase in perinatal mortality. The mechanism of hypothyroidism in pre-eclampsia is controversial and may be related to decreased plasma protein concentrations and increased endothelin levels.

Methods: This was a prospective comparative study in 100 women; out of them, 50 were normal pregnant women in the control group and 50 preeclamptic women in the case group. Thyroid hormones, total FT3, FT4 and TSH were analyzed in these subjects. The cases of pre-eclampsia characterized by elevation of blood pressure of more than $140 \mathrm{mmHg}$ systolic or more than $90 \mathrm{mmHg}$ diastolic with proteinuria (more than $300 \mathrm{mg} / \mathrm{l}$ in 24 hours specimen) after 37 weeks of gestation in previously normotensive nonproteinuric pregnant women.

Results: Incidence of hypothyroidism is high in the study group (30\%) compared to the control (14\%). Furthermore, the maximum subjects were observed with euthyroidism $43(86 \%)$ in the control group, whereas subclinical hypothyroidism $23(46 \%)$ was observed highest in the preeclamptic group. Out of the 50 preeclamptic patients, 13 $(26 \%)$ belonged to the severe whereas $37(74 \%)$ belonged to the mild pre-eclampsia group.

Conclusions: The study concluded that the pre-eclamptics have a higher incidenceof hypothyroidism (SCH) in contrast to the normotensive women, and there is a correlation between the severity ofpre-eclampsia and hypothyroidism.
\end{abstract}

Keywords: Thyroid hormones, Preeclampsia, Normotensive, Pregnancy

\section{INTRODUCTION}

Changes in thyroid function are well-documented during a normal pregnancy, but there is few evidence on thyroid function during a difficult pregnancy. During pregnancy, there is an increase in thyroid demand and iodine intake and thyroid hormone synthesis. Thyroxine binding globulin (TBG) levels rise in response to oestrogen, and the placenta produces an overabundance of thyroid stimulatory substances, such as hCG. The alpha subunit of hCG is identical to that of TSH and has only a minor thyrotropic effect. ${ }^{1}$

One of the reasons for high blood pressure has been identified as hypothyroidism. ${ }^{2}$ Because of placental malfunction, oestrogen production decreases in preeclampsia, resulting in reduced levels of TBG, triiodothyronine (TT3), and thyroxin (TT4), as well as foetal growth retardation. ${ }^{3}$ According to mounting data, oxidative stress and impaired endothelial cell function may play a role in preeclampsia. ${ }^{4-6}$ Apart from renal failure, oxidative stress has been postulated to contribute to the hyperuricemia seen in pre-eclampsia. ${ }^{7}$ Furthermore, increased superoxide anion levels in pre-eclampsia may inactivate $\mathrm{NO}$, resulting in decreased relaxation and increased vasoconstriction. ${ }^{6,8}$ According to experimental research, the release of NO is changed in hypothyroidism, and the ensuing endothelial cell dysfunction could represent a pathogenetic basis for hypothyroidism in preeclampsia. $^{9}$

The present study was initiated to evaluate thyroid hormones in preeclamptic women and compare them with that of normotensive pregnant women and signify that 
hypothyroidism in pre-eclampsia correlates with the severity of pre-eclampsia.

\section{METHODS}

\section{Study design}

The study is a prospective comparative study to measure the prevalence of hypothyroidism in women presenting with pre-eclampsia (>37 weeks) and compare it with normotensive patients admitted for safe confinement.

\section{Sample size}

Sample size for study was the 100 women constituting, 50 nor-motensive and 50 pre-eclamptic women.

\section{Inclusion criteria}

\section{For case pre-eclampsia group}

Inclusion criteria of pre-eclampsia were blood pressure of $\geq 140 / 90 \mathrm{mmHg}$ on at least two occasions, six hours apart and/or proteinuria. All subjects were diagnosed case of pre-eclampsia and previously normotensive.

\section{For controls group}

Participants should be pregnant women $>37$ weeks and normotensive were included in the study.

\section{Exclusion criteria}

Subjects with previous H/O medical renal and hepatic disease, hyperthyroidism and endocrine disorders, RHD, subjects with <37 weeks gestation, subjects with any chronic drugs and multiple gestations and molar pregnancy were excluded from the study.

\section{Study period}

The present study was performed at in-patient/ out-patient Kanyakumari government medical college and hospital, Tamil Nadu in OG department from April 2021 to December 2021.

\section{Study method}

Pregnant women $>37$ weeks gestation with blood pressure more than $140 / 90 \mathrm{mmHg}$ with proteinuria (more than 300 $\mathrm{mg} / \mathrm{dl}$ in 24 hours urine) on 2 or more occasions at least 6 hours apart were diagnosed as pre-eclampsia were selected for the study.

Healthy normotensive women admitted in the labour room are selected as the control for this study with informed consent; data regarding the age, symptoms, parity, height, weight are to be recorded.
The $10 \mathrm{ml}$ venous blood to be drawn for thyroid hormone analysis (FT3, FT4, TSH) using chemiluminescent assay. Particulars of the women are to be noted, such as name, age, symptoms, menstrual history for menarche, last menstrual period and past menstrual cycles, history of present pregnancy. In addition, past obstetric history to be asked for the duration of marriage, infertility, gravidity and parity status, recurrent abortions, pre-eclampsia, growth restriction, low birth weight, preterm delivery, prematurity, late pregnancy losses, neonatal deaths, and mental retardation in the previous pregnancy.

Past medical history was asked for any associated medical disorders like diabetes, thyroid disorders, exposure to radiation or autoimmune disorders. Significant surgical history family history was also requested.

Assessment of thyroid status of cases and controls were done with serum free T3, T4 and TSH for which $10 \mathrm{ml}$ venous blood sample was taken from the cubital vein: In cases after the diagnosis of pre-eclampsia was made but before the initiation of the antihypertensive treatment and before the delivery and in controls, after admission. All samples were sent to the laboratory where Sera were separated and stored at-200c until assayed

Free T4 and TSH were measured using a fully automated chemiluminescence system (CLIA kits). Further, depending upon the fT4 and fT3 values, all women were classified as subclinical hypothyroidism, euthyroid, subclinical hypothyroidism and overt hypothyroidism

\section{Data analysis and statistical methods}

Data entry was done by the principal investigator in proforma, which was prepared based on a data abstraction sheet and exported to SPSS for analysis.

\section{RESULTS}

In my study, most of the patients were in the age group of 21-30 years in both groups. Of 50 patients, $26(52 \%)$ in the case group and $50(60 \%)$ patients in the control group were observed in 21 to 30 years. The incidence of pre-eclampsia was more common in the extremes of age group (Table 1).

Table 1: Distribution of age group of subjects.

\begin{tabular}{|lll|}
\hline Age (Years) & Cases & Control \\
\hline$\leq \mathbf{2 0}$ & 12 & 9 \\
\hline $\mathbf{2 1 - 3 0}$ & 26 & 30 \\
\hline $\mathbf{3 1 - 4 0}$ & 12 & 11 \\
\hline Total & 50 & 50 \\
\hline
\end{tabular}

The obstetric score in both group patients was carried out, and it was found that maximum subjects were reported in primi $26(52 \%)$ in the case group and $27(54 \%)$ in the control group (Table 2 and Figure 1). 
The mean TSH and FT4 values of all subjects were recorded, and it was observed that the mean TSH (3.4 \pm 1.3$)$ values of case group subjects were significantly higher than control groups subjects (1.8 \pm 0.9$)$. A similar observation was also observed with mean values of FT4 (Table 3). The mean FT4 values during the $1^{\text {st }}, 2^{\text {nd }}$ and $3^{\text {rd }}$ trimester were reported to be $2.5 \mathrm{mIU} / \mathrm{L}, 3 \mathrm{mIU} / \mathrm{L}$ and $3 \mathrm{~m}$ $\mathrm{IU} / \mathrm{L}$, respectively, in present study.

Table 2: Observation of obstetric score of subjects.

\begin{tabular}{|ll|l|}
\hline Obstetric score & Study & Control \\
\hline Primi & 26 & 27 \\
\hline $\begin{array}{l}\text { Multi with previous } \\
\text { normal delivery }\end{array}$ & 14 & 18 \\
\hline Multi with pre LSCS & 10 & 5 \\
\hline Total & 50 & 50 \\
\hline
\end{tabular}

The different types of hypothyroidism in subjects were recorded during the study. The prevalence of subclinical hypothyroidism of $\mathrm{p}$ re-eclampsia women (case group) was $23(46 \%)$ and $6(12 \%)$ of normotensive women (Control group). On the other hand, overt hypothyroidism was contributed to $7(14 \%)$ in the case group while $1(2 \%)$ in the control group (Table 4).

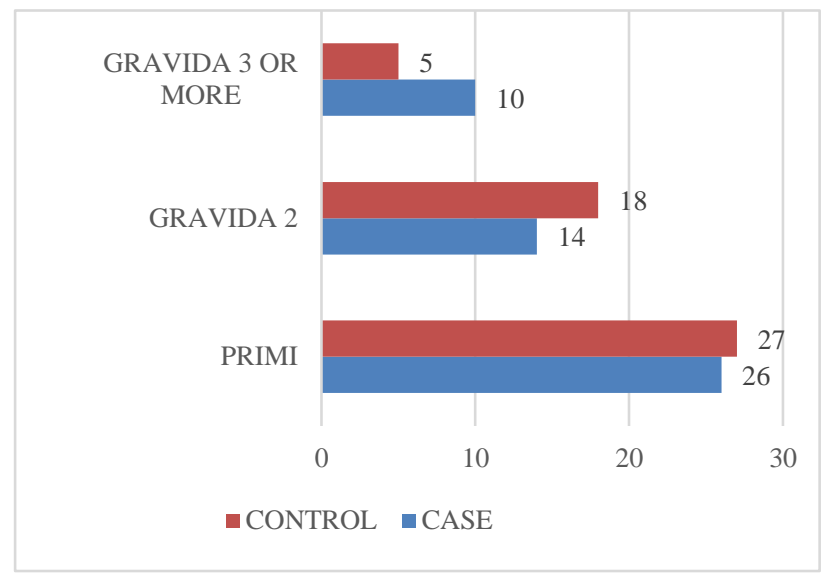

Figure 1: Observation of obstetric score of subjects.

Table 3: Observation of mean values of TSH, FT4 of all subjects.

\begin{tabular}{|llllll|}
\hline Variables & Cases, mean \pm SD & Control & T value & DOF & P value \\
TSH & $3.4 \pm 1.3$ & $1.8 \pm 0.9$ & 0.0001 & 198 & $<0.005$ \\
\hline FT4 & 1.070 .33 & $0.93 \pm 0.28$ & 0.002 & 198 & $<0.005$ \\
\hline
\end{tabular}

Table 4: Observations of hypothyroidism among both groups.

\begin{tabular}{|c|c|c|c|c|}
\hline Classification & Case & Control & Total & $\mathbf{P}$ \\
\hline Euthyroid & 20 & 43 & 63 & \multirow{4}{*}{0.0001} \\
\hline $\begin{array}{l}\text { Subclinical } \\
\text { hypothyroid }\end{array}$ & 23 & 6 & 29 & \\
\hline $\begin{array}{l}\text { Overt } \\
\text { hypothyroid }\end{array}$ & 7 & 1 & 8 & \\
\hline Total & 50 & 50 & 100 & \\
\hline
\end{tabular}

Women were also studied in the present study of the severity of other hypothyroidism observed in Preeclampsia. In subclinical hypothyroidism, 3 (23\%) subjects were observed severity, whereas, in overt hypothyroidism, $6(46 \%)$ patients were reported with severity (Table 5).

Table 5: Observation of severity of hypothyroidism in preeclampsia women.

\begin{tabular}{|llll|}
\hline Classification & Mild & Severe & Total \\
\hline Subclinical hypothyroid & 20 & 3 & 23 \\
\hline Overt hypothyroid & 1 & 6 & 7 \\
\hline Euthyroid & 16 & 4 & 20 \\
\hline Total & 37 & 13 & 50 \\
\hline
\end{tabular}

\section{DISCUSSION}

The age distribution of patients included in our study ranged from 18 to 40 years. However, most of them belonged to the less than 21-30 years in both the groups. The mean age of the patients in the control and study group was $28.07 \pm 4.89$ and $24.42 \pm 4.93$ years, respectively. In a similar study done by Kumar et al comparing preeclamptics with normotensive women, the mean age of the study group and the control group was $28.4 \pm 6.24$ years and $27.5 \pm 5.91$ years, respectively, which is quite similar to our study. ${ }^{9}$

In the present study majority of the subjects in both groups were observed in primi pregnancy (26 subjects in preeclamptic and 27 in the control group). Whereas minimum subjects were observed in gravid 3 or more category in both the groups (10 subjects in preeclamptic and 5 in control group). These findings in the present study are in accordance with earlier reported studies. ${ }^{10}$

TSH, free T4 was done for both the groups and the results were analysed. The mean TSH value in the preeclamptic group is more than the controls in our study $(3.4 \pm 1.3$ vs $1.8 \pm 0.9)$ and is significant $(\mathrm{p}<0.005)$. Our study's mean free $\mathrm{T} 4$ values in pre-eclampsia vs controls are $1.07 \pm 0.33$ vs $1.07 \pm 0.28$ which remains within the normal trimesterspecific range of FT4. However, the preeclamptic group had a mean FT4 level lower than the controls, and the difference was significant statistically $(\mathrm{p}<0.005)$. In a similar study by Tehrani et al the mean FT4 is not significantly different in the two groups. ${ }^{11}$ However, the mean TSH value was significantly higher in the preeclamptic women than in the controls $(\mathrm{p}<0.001)$. This is partly comparable to our study, where the mean TSH 
and FT4 are significantly different, with the PE group having a high mean TSH and a low mean FT4.

The different categories of hypothyroidism among all subjects were evaluated. The control group had $43(86 \%)$ euthyroid Subjects, 6 (12\%) subclinical hypothyroid and overthypothyroid $1(2 \%)$. In the pre-eclampsia group, 20 $(40 \%)$ were euthyroid, $23(46 \%)$ were subclinical hypothyroid, 7 (14\%) were overt hypothyroid. These findings are in accordance with the previous literature stating that preeclamptic women have a higher incidence and prevalence ofbiochemical hypothyroidism than the normotensive population. ${ }^{12}$

Incidence of hypothyroidism is high in the study group $(30 \%)$ compared to the control $(14 \%)$. Thus, subclinical hypothyroidism is more common in the preeclamptic group in the present study. In another Indian study, the mean TSH titers in the preeclamptic pregnancies have been reported to be $3.8 \pm 0.53 \mathrm{mIU} / \mathrm{ml}$, while in the normal pregnancies, it was $2.3 \pm 0.24 \mathrm{mIU} / \mathrm{ml}$ which again is comparable to the present study. ${ }^{13}$

This study also analysed the relationship between the severity of pre-eclampsia and hypothyroidism. Out of the 50 preeclamptic patients, $13(26 \%)$ belonged to the severe and $37(74 \%)$ belonged to the mild pre-eclampsia group. These findings strongly suggest an association between the severity of pre-eclampsia and hypothyroidism. ${ }^{14}$

\section{Limitations}

Small sample size, multiple comparisons without corrections, observational design and risk for confounding

\section{CONCLUSION}

In this study, the pre-eclamptics have a higher incidence of subclinical hypothyroidism than normotensive women. Furthermore, there is a correlation between the severity of pre-eclampsia and hypothyroidism. Therefore, the treatment of overt hypothyroidism and subclinical hypothyroidism is mandatory.

Funding: No funding sources Conflict of interest: None declared

Ethical approval: The study was approved by the Institutional Ethics Committee

\section{REFERENCES}

1. Brent GA. Maternal thyroid function: interpretation of thyroid function tests in pregnancy. Clin Obstet Gynecol. 1997;40(1):3-15.

2. Endo T, Komiya I, Tsukui T. Reevaluation of a possible high incidence of hypertensive in hypothyroid patients. Am Heart J. 1979;98(6):684-8.

3. Kaye E, Sahin Y, Ozkececi Z, Pasaoglu H. Relation between birth weight and thyroid function in preeclampsia-eclampsia. Gynecol Obstet invest. 1994;37(1):30-3.

4. Kharb S, Gulati N, Singh V, Singh GP. Lipid peroxidation and vitamin $\mathrm{E}$ levels in pre-eclampsia. Gynecol Obstet Invest. 1998;46(4):238-40.

5. Kharb S. Total free radical trapping antioxidant potential in pre-eclampsia. Int $\mathrm{J}$ Gynecol Obstet. 2000;69(1):23-6.

6. Kumar CA, Das UN. Lipid peroxides, anti-oxidants and nitric oxide in patients with pre-eclampsia and essential hypertension. Med Sci Monitor. 2000;6(5):901-7.

7. Kharb S, Gulati N, Singh V, Singh GP. Superoxide formation and glutathione levels in patients with preeclampsia. Gynecol Obstet Invest. 2000;49(1):28-30.

8. Kharb S, Singh GP. Hyperuricemia, Oxidative stress in pre-eclampsia. Clin Chim Acta. 2001;305(1-2): 201-3.

9. Kumar A, Ghosh BK, Murthy NS. Maternal thyroid hormonal status in pre-eclampsia Indian J Med Sci. 2005;59(2):57-63.

10. Lao TT, Chin RKH, Swaminathan R, Lam YM. Maternal thyroid hormones and outcome of preeclamptic pregnancies. $\mathrm{Br} \mathrm{j}$ Obstet Gynaecol. 1990;97(1):71-4.

11. Tehrani FR, Pakniyat H, Naji A, Asefzadeg S. Thyroid hormone variations in pre-eclampsia. J Qazvin University Med Sci. 2003;24:18-23.

12. Tolino A, De Concilus B, Montemagno U. Thyroid hormones in human pregnancy. Acta Obstet Gynecol Scan. 1985;64(7):557-9.

13. Basbug M, Aygen E, Tayyar M, Tutuş A, Kaya E, Oktem O. Correlation between maternal thyroid function tests and endothetim in pre-eclampsiaeclampsia. Obstet Gynecol. 1999;94(4):551-5.

14. Qualam HS, Al-Kaisi IJ, Hinduwi M, Hiasat MS, Awamleh I, Hamaideh AH et al. Severe pre-eclampsia and maternal thyroid function. J Obstet Gynaecol. 2003;23(3):244-6.

Cite this article as: Aravazhi M, Ajit R, Breetha V, Sruthi S. Comparison of thyroid hormone status between pre-eclampsia and normotensive pregnancy after 37 weeks. Int J Reprod Contracept Obstet Gynecol 2022;11:849-52. 